\title{
Biosorption of cationic dyes on breadfruit (Artocarpus altilis) peel and core
}

\author{
Namal Priyantha, ${ }^{1,2}$. Linda B. L. Lim ${ }^{3}$. D. T. B. Tennakoon ${ }^{2}$ Elaine T. Z. Liaw ${ }^{3} \cdot$ Chieng Hei Ing $^{3}$. \\ Anushka B. Liyandeniya ${ }^{1,2}$
}

Received: 26 September 2017 / Accepted: 12 December 2017 / Published online: 13 February 2018

(c) The Author(s) 2018. This article is an open access publication

\begin{abstract}
The purpose of this research is to investigate biosorption characteristics of two cationic dyes, methylene blue (MB) and methyl violet 2B (MV), on breadfruit (Artocarpus altilis) peel and core. Characterization of breadfruit waste was conducted using surface titrations, thermogravimetry, and Fourier transform infrared spectroscopy. The extent of interaction between dyes and each biosorbent was monitored by absorbance measurements, which was then used in isotherm, thermodynamics, and kinetics analysis. Biosorption of MB and MV on breadfruit peel and core reaches equilibrium in 150-180 min. All four systems under investigation (MB-breadfruit peel, MB-breadfruit core, MV-breadfruit peel, and MV-breadfruit core) show similar extent of dye removal of about $80 \%$ under the conditions employed. Biosorption of both dyes on both biosorbents follow the Langmuir adsorption isotherm model at the ambient $\mathrm{pH}$, at which the breadfruit surface bears a negative charge. Kinetics of biosorption of MB on breadfruit waste is so fast that it is not possible to determine the order of adsorption kinetics at the concentration level employed. The rate of biosorption of MV on breadfruit waste is smaller and follows pseudo second order kinetics with rate constants of 153.5 and $31.7 \mathrm{~g} \mathrm{mmol}^{-1} \mathrm{~min}^{-1}$ for peel and core, respectively. Thermodynamics studies conducted for each biosorption system provide negative $\Delta G^{\Theta}, \Delta H^{\Theta}$ and $\Delta S^{\Theta}$ values with the maximum biosorption for $\mathrm{MB}$ at the ambient temperature of $24^{\circ} \mathrm{C}$, while that for MV is obtained between 40 and $50{ }^{\circ} \mathrm{C}$. All four biosorption systems show spontaneity and exothermic behaviour to varying degrees.
\end{abstract}

Keywords Breadfruit waste $\cdot$ Methylene blue $\cdot$ Methyl violet 2B $\cdot$ Equilibrium studies $\cdot$ Kinetics

\section{Introduction}

Dyes are used widely in industries, such as textile, cosmetics, food, plastics and paper, and other industries where coloration of objects is needed (Safa and Bhatti 2011; Ahmad and Alrozi 2011; Farah et al. 2007). Approximately more than 10,000 dyes are available commercially and more than $7 \times 10^{5}$ tonnes of dyestuff are produced yearly (Bharathi and Ramesh 2013a; Elkady et al. 2011; Lee et al. 2006;

Namal Priyantha

namalpriyantha@pdn.ac.lk

1 Department of Chemistry, University of Peradeniya, Peradeniya, Sri Lanka

2 Postgraduate Institute of Science, University of Peradeniya, Peradeniya, Sri Lanka

3 Department of Chemistry, Faculty of Science, Universiti Brunei Darussalam, Jalan Tungku Link, Gadong 1410, Brunei
Rafatullah et al. 2010). Amount of dyes disposed into the wastewater or natural ecosystem is on the increase, resulting in polluting the water and causing serious problems to the environment. Although dyes are a class of industrially important substances, they are stable and difficult to be degraded once they enter the natural ecosystem (Gupta and Suhas 2009; Uddin et al. 2009; Dogan et al. 2009; Suteu et al. 2009). Dye effluents are toxic, not only to the aquatic biota, but also to mankind. Aquatic biota is affected when dyes are present on the surface of water as the extent of photosynthesis of aquatic plants is reduced (Safa and Bhatti 2011; Ju et al. 2008), while humans are affected as synthetic dyes would cause many health effects (Safa and Bhatti 2011; Rahchamani et al. 2011).

Methylene blue (MB, $\mathrm{C}_{16} \mathrm{H}_{18} \mathrm{~N}_{3} \mathrm{SCl}$ ) and methyl violet 2B (MV, $\mathrm{C}_{24} \mathrm{H}_{28} \mathrm{ClN}_{3}$ ) are two cationic industrial dyes, which are extensively used in the textile industry (Fig. 1) (Ponnusami et al. 2009). Additionally, MV is used in Gramstaining, as an anti-allergen, and as a bactericide ( $\mathrm{Li}$ et al. 
Fig. 1 Structure of a methylene blue (MB) and $\mathbf{b}$ methyl violet 2B (MV)<smiles>CN(C)c1ccc2c(c1)SC1=CC([N+](C)C)C=CC1=N2</smiles>

(a)<smiles>C[NH+]=C1C=CC(=C(c2ccc(N(C)C)cc2)c2ccc(N(C)C)cc2)C=C1</smiles>

(b)
2010). Despite having vast applications, these two dyes have various harmful effects on living organisms on short periods of exposure (Ponnusami et al. 2009; El-Sayed 2011). Acute exposure of MB is found to cause increased heart rate, shock, vomiting, jaundice, quadriplegia (paralysis), cyanosis, tissue necrosis and Heinz body formation in humans (Gupta et al. 2011; Kumar and Kumaran 2005). Ingestion of MB causes burning sensation, nausea, diarrhoea, gastritis, haemolytic anaemia, hyperbilirubinemia and acute renal failure (Rafatullah et al. 2010; Ponnusami et al. 2009; Bhattacharyya and Sharma 2005). On the other hand, exposure to MV causes skin and eye irritation, and it is harmful if swallowed or absorbed via skin (Li et al. 2010; Mittal et al. 2008).

Due to environmental and health impacts of dyes, several methods have been developed to remove them from wastewater before they are disposed of to the natural ecosystem. Chemical methods are not suitable for ionic dyes due to their high solubility. Physical methods, which include precipitation, ion exchange, membrane filtration, electrochemical destruction, irradiation and adsorption, lead to the formation of sludge and various by-products. On the other hand, biological methods are unable to remove dyes from effluents effectively. Amongst the above stated techniques, adsorption is one of the best as it provides means of removing different types of colouring materials with the aid of suitable adsorbents, such as granulated or powdered activated charcoal (Fei et al. 2012; Mezohegyia et al. 2012; Lim et al. 2015; Ahmad and Hameed 2010). As the production of good quality activated charcoal is expensive, low cost adsorbents are being researched upon as viable alternatives.

Biosorption is a physiochemical process that allows foreign substances to bind onto the cellular structure of the biomass. In this context, research on the use of biomass and agricultural waste, in their natural or modified forms, in treatment of wastewater has been increased in recent years (Lim et al. 2014; Tripathi and Ranjan 2015). For example, activated sludge biomass, containing insoluble metal hydroxides and other salts, has shown a significantly high-dye uptake capacity (Rafatullah et al. 2010; Bharathi and Ramesh 2013b; Otero et al. 2003). Although biosorption is mainly used for metal binding, this phenomenon can be extended for toxic dye removal as an economical and alternative approach for treatment of industrial wastewater contributing towards environmental remediation. The extent of removal of a pollutant depends on equilibrium and kinetics, both of which are controlled by experimental conditions. Consequently, investigation of biosorption of a pollutant by a biomass is a complex issue. Nevertheless, biosorption is a promising option to conventional processes for the removal of dyes and other pollutants owing to the highly selective and efficient nature of biosorbents (Gupta and Suhas 2009). Nonetheless, these techniques are still under development.

Biosorption of MB and MV on breadfruit peel and core, which has no economical value, has not been reported to the best of our knowledge. Hence, the study reported here, which is on detailed investigation on parameter optimization, equilibrium and kinetics of interaction of the above two dyes with breadfruit peel and core, would provide useful information on the potential use of these biosorbents for the removal of the two toxic dyes under investigation. Further, molecular level information can be obtained through Fourier transform infrared spectral (FTIR) data before and after sorption.

\section{Materials and methods}

\section{Reagents and instrumentation}

\section{Chemicals and reagents}

Mineral acids $\left(\mathrm{HNO}_{3}\right.$ and $\left.\mathrm{HCl}\right)$ were purchased from $\mathrm{BDH}$ Chemicals Ltd. and $\mathrm{NaOH}$ was purchased from Ajax Chemicals. The dyes used, MB and MV, were purchased from Sigma-Aldrich Corporation. Acids and bases were standardized before they were used in experiments. All experiments were performed at ambient temperature. 


\section{Instrumentation}

UV-Vis spectrophotometer (Shimadzu Model UV-1601PC) and FTIR spectrophotometer (Shimadzu Model IRPrestige-21) were used for absorbance measurements of solutions and solids, respectively. Thermogravimetric apparatus (Scinco Instruments Model STA N-650) was used to monitor mass and temperature changes upon firing, and Thermo-Scientific Orion 2 Star Bench-top pH meter was used in monitoring the $\mathrm{pH}$ of solutions.

\section{Research methodology}

\section{Determination of the surface charge of breadfruit waste}

A suspension of fine powder of each of breadfruit peel and core of $20.0 \mathrm{~g} \mathrm{~L}^{-1}$ in $0.10 \mathrm{M} \mathrm{KNO}_{3}$ solution was stirred for $12 \mathrm{~h}$ in a closed container to form a homogeneous suspension. The initial $\mathrm{pH}$ of the suspension was lowered to a known $\mathrm{pH}$ (3.5) using $0.10 \mathrm{M} \mathrm{HNO}_{3}$. The resulting solution was then titrated with $0.10 \mathrm{M} \mathrm{NaOH}$ solution until the $\mathrm{pH}$ reached 9.5. A back titration was carried out using the same $\mathrm{HNO}_{3}$ solution to ensure the same changes in $\mathrm{pH}$ during the titration.

\section{Preparation of dye solutions}

MB (MW $=319.5$, reported $\lambda_{\max }=664.4 \mathrm{~nm}$ ) and MV (MW $=394.0$, reported $\lambda_{\max }=584.0 \mathrm{~nm}$ ) were used without further purification. A stock solution of $1000 \mathrm{ppm}$ of each dye was prepared and diluted with distilled water to prepare diluted standard solutions.

\section{Preparation of biosorbent samples}

Samples used in this study were peel and core of breadfruit, which were separated from the fruit, purchased randomly from the local market, and dried in an oven at $80{ }^{\circ} \mathrm{C}$ until there was no further mass loss. Although some organic matter may be decomposed at this temperature, complete drying is important for long term experiments and for extrapolating results obtained toward industrial applications. The dried samples were then blended and sieved to obtain the fraction with particle sizes between 355 and $855 \mu \mathrm{m}$, and used for experiments.

\section{Optimization of experimental parameters}

A sample of $50.0 \mathrm{~mL}$ of each dye solution (10 ppm) was treated with $0.10 \mathrm{~g}$ of the biosorbent and shaken at $250 \mathrm{rpm}$ at ambient temperature for different shaking times from 30 to $240 \mathrm{~min}$. After shaking, each solution was filtered using a ceramic sieve, and the absorbance of the filtrate was determined at the appropriate $\lambda_{\max }$ value for the determination of the remaining dye content to optimize the shaking time. Then, $50.0 \mathrm{~mL}$ of each dye solution was shaken with $0.10 \mathrm{~g}$ of the biosorbent for the optimum shaking time, and the contents were allowed to settle for different time periods up to $240 \mathrm{~min}$. Each filtrate was analysed as stated earlier to determine the optimum settling time. The $\mathrm{pH}$ of each dye solution $(10 \mathrm{ppm})$ was then adjusted to a value ranging from 2.0 to 9.0 , and an aliquot of $50.0 \mathrm{~mL}$ of each solution was treated with $0.10 \mathrm{~g}$ of each biosorbent for optimum shaking time and optimum settling time. Each solution was filtered, and the filtrate was analysed as stated earlier to determine the optimum $\mathrm{pH}$. Each experiment was performed in duplicate/triplicate, and the average values were reported.

\section{Equilibrium studies of biosorption}

Dye solutions of a series of concentrations $(0-1000 \mathrm{ppm})$ was treated with each biosorbent in 1:500 solid/solution ratio, and the optimum shaking and settling time periods were allowed for each system to reach equilibrium. Solutions were filtered, and filtrates were analysed using UV-Vis spectrophotometer. The results obtained were then used for isotherm analysis. The same conditions were used for solutions of $100 \mathrm{ppm} \mathrm{MB}$ and $100 \mathrm{ppm}$ MV separately at different solution temperatures varying from ambient value $24{ }^{\circ} \mathrm{C}$ to $70{ }^{\circ} \mathrm{C}$ to determine thermodynamic properties.

\section{Kinetics studies of biosorption}

A sample of $0.10 \mathrm{~g}$ of each biosorbent was mixed with $50.0 \mathrm{~mL}$ of each dye solution (10 ppm), and the suspension was stirred immediately after mixing. Samples were withdrawn at 1 min intervals until the equilibrium was reached. Each solution was filtered, and the filtrate was analysed using UV-Vis spectrophotometer. Results were then used for the investigation of kinetics models.

\section{Results and discussion}

\section{Characterization of breadfruit waste}

Surface titration curves obtained for breadfruit peel and core in $0.1 \mathrm{M} \mathrm{KNO}_{3}$ solution are shown in Fig. 2. The surface charge density for each addition of $\mathrm{NaOH}$, which is needed for the construction of the curves in the figure, was calculated using a standard equation (Priyantha and Bandaranayaka 2011). The surface charge of breadfruit peel and core is negative at $\mathrm{pH}$ greater than 4.6 and 4.2 , respectively. Both the peel and the core would therefore show direct Coulombic attraction toward cationic dyes beyond the above stated $\mathrm{pH}$. It can be further argued that, at the ambient $\mathrm{pH}$ of 5.8 


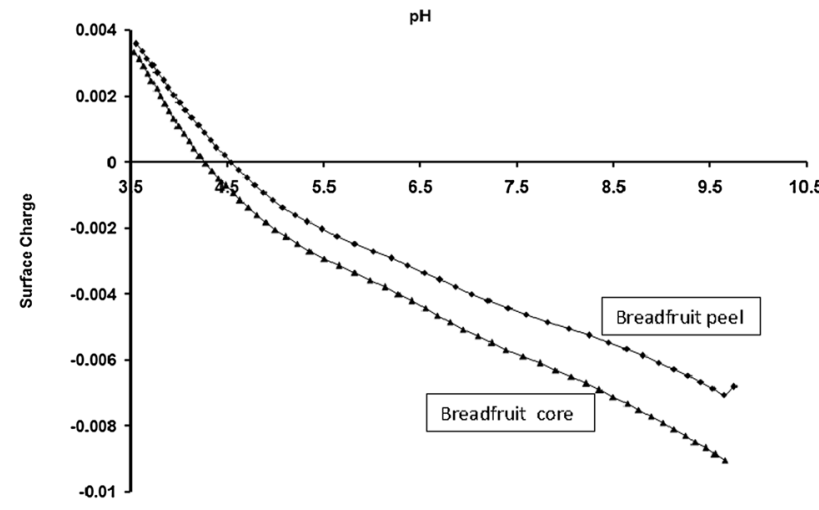

Fig. 2 Surface charge of breadfruit peel and breadfruit core as functions of $\mathrm{pH}$

for MB solutions of the concentration used, the core would show stronger affinity toward MB as compared to that of peel. Similar argument would hold for MV as well at its ambient $\mathrm{pH}$ of 5.2. Consequently, no $\mathrm{pH}$ adjustment is necessary for the investigation of adsorption of these dyes.

Thermogravimetric curves constructed for breadfruit peel and core indicate three distinct temperature regions of mass reduction; around $100^{\circ} \mathrm{C}$, and in the ranges from 200 to $320^{\circ} \mathrm{C}$, and from 400 to $500{ }^{\circ} \mathrm{C}$. The average mass reductions in these temperature regions are 12,42 and $21 \%$, respectively. The first mass reduction is due the evaporation of moisture (endothermic), while the other two reductions associated with exothermic reactions are due to the combustion of different types of organic compounds present in breadfruit waste, including phenolic substances and amino acids. The large decrease in mass reduction and energy released are indicative of the organic nature of the biomass. As there are no significant differences between the curves of breadfruit peel and core, the thermogravimetric results of only breadfruit peel are reported (Fig. 3).

\section{Optimisation of experimental parameters for biosorption of MB and MV by breadfruit peel and core}

The extent of biosorption of dyes is affected by experimental factors, such as shaking time, settling time, and the $\mathrm{pH}$ of the medium. Thus, the effect of these factors on the extent of biosorption of each dye was investigated to optimize parameters for most efficient biosorption. Effect of shaking time on the extent of removal is an important parameter in the study of biosorption, as it provides the information on time required to reach equilibrium, which would depend on the specific system. Based on the extent of removal-shaking time relationship, performed over a period of $4.0 \mathrm{~h}$, the time required to reach equilibrium was selected as the optimum shaking time for continuation of sorption experiments

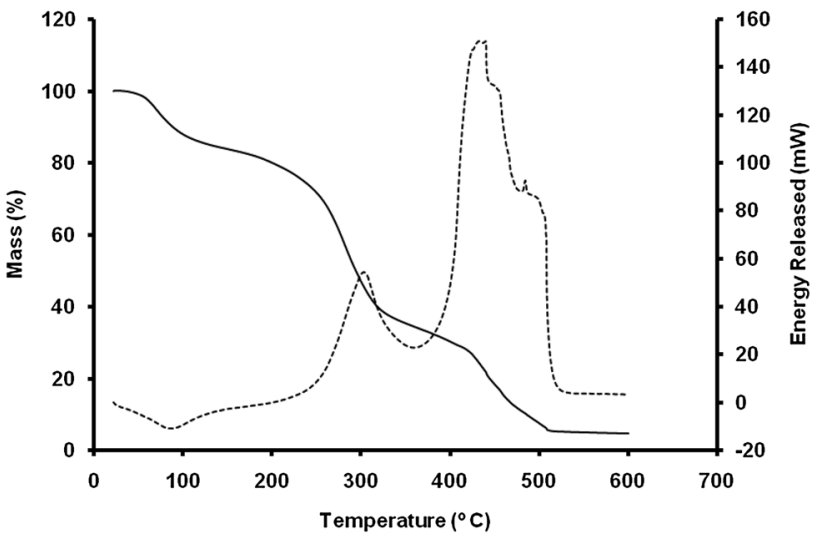

Fig. 3 Thermal gravimetric curve (continuous line) and associated energy release curve (dashed lines) for breadfruit peel

for each adsorbate-adsorbent system. The time periods selected in this study, as well as for biosorption studies that have been previously reported, are listed in Table 1 . Shorter time period required to reach equilibrium of the MBbreadfruit core system, as compared to that of breadfruit peel could be due to more negative surface charge of the core. However, for comparison of the extent of removal, a shaking time of 180 min was used for each biosorption system. Although the shaking time required to reach equilibrium depends on many factors, such as concentration of the adsorbate, solution temperature, adsorbent/adsorbate ratio, shaking speed, and type and particle size of the adsorbent, the values experimentally determined for $10 \mathrm{ppm}$ dye solutions under the experimental conditions employed are comparable with those reported for many other biosorbents.

The extent of biosorption of MB and MV by both breadfruit peel and core rapidly increases initially and reaches equilibrium after sufficient shaking time period is allowed. At the optimum shaking time, it is expected that the adsorbent/adsorbate system has reached equilibrium, and hence,

Table 1 Comparison of optimum shaking time for biosorption of MB and MV by various substances

\begin{tabular}{llll}
\hline Adsorbent & Adsorbate & $\begin{array}{l}\text { Shaking } \\
\text { time (min) }\end{array}$ & References \\
\hline Breadfruit peel & MB & 180 & This work \\
Breadfruit core & MB & 150 & This work \\
Jackfruit peel & MB & 180 & (Maurya et al. 2006) \\
Pomelo peel & MB & 315 & Namasivayam and \\
& & & Sureshkumar \\
Breadfruit peel & MV & 180 & This work \\
Breadfruit core & MV & 180 & This work \\
Palm kernel fibre & MV & 140 & Ofomaja et al. (2011) \\
Sunflower seed hull & MV & 135 & Hameed et al. (2008) \\
\hline
\end{tabular}


there would be no significant effect of settling time. This was experimentally proven by observing a constant extent of removal determined at the optimum shaking time during a settling time period increased up to $240 \mathrm{~min}$ for both dyes on each biosorbent. However, a settling time period of $90 \mathrm{~min}$ was chosen in the study of biosorption of both dyes on each biosorbent to ensure that the system is at equilibrium.

Medium $\mathrm{pH}$ does not significantly affect the adsorption behaviour of dyes in contrast to the situation of the sorption of metal ions. However, structural changes of dyes occur at extreme $\mathrm{pH}$ values, and further, $\mathrm{H}_{3} \mathrm{O}^{+}$competes with adsorption sites at low $\mathrm{pH}$ values, thereby affecting the sorption equilibrium. As MB and MV do not change their absorption characteristics within the $\mathrm{pH}$ range between 4.0 and 8.0 (Table 2),

Table 2 Absorbance values for $10 \mathrm{ppm}$ solutions of MB and MV at respective $\lambda_{\max }$ values (experimentally determined) in solutions of different $\mathrm{pH}$ values

\begin{tabular}{llllll}
\hline $\mathrm{pH}$ & \multicolumn{2}{l}{$\mathrm{MB}$} & & \multicolumn{2}{l}{$\mathrm{MV}$} \\
\cline { 5 - 6 } & $\lambda_{\max }$ & Absorbance & & $\lambda_{\max }$ & Absorbance \\
\hline 2.0 & 664 & 1.96 & & 588 & 1.12 \\
4.0 & 664 & 1.99 & & 584 & 1.91 \\
6.0 & 664 & 1.99 & 584 & 1.88 \\
8.0 & 664 & 1.99 & 584 & 1.83 \\
10.0 & 664 & 1.91 & 585 & 1.63 \\
12.0 & 664 & 1.77 & 586 & 0.24 \\
Ambient & & & & \\
$5.8(\mathrm{MB})$ & 664 & 1.95 & & - & - \\
$5.2(\mathrm{MV})$ & - & - & 585 & 1.94 \\
\hline
\end{tabular}

subsequent sorption experiments were conducted at respective ambient $\mathrm{pH}$ values of 5.8 and 5.2, respectively.

\section{Sorption isotherm studies of MB and MV on breadfruit peel and core}

The equilibrium adsorption isotherm provides basic information in explaining the interactive behaviour between a sorbate and a sorbent, which is important in the design and analysis of sorption systems (Maurya et al. 2006; Namasivayam and Sureshkumar 2008). Figure 4 shows isotherm plots constructed for both MB and MV dyes as a function of the initial dye concentration within the range of $0-1000 \mathrm{ppm}$. Levelling off the amount of adsorption of each dye on both breadfruit peel and core is indicative of the completion of a monolayer, and prevents further sorption leading to multilayer coverage, which is typical for many adsorption systems on natural adsorbents (Maurya et al. 2008).

Detailed investigation of sorption equilibria of the above dyes on the biosorbent can be performed through the Langmuir adsorption isotherm model, which assumes that a given site can accommodate only a single sorbent species, limiting the maximum coverage to a monolayer. It is given by,

$\frac{C_{\mathrm{e}}}{q_{\mathrm{e}}}=\frac{1}{q_{\max } K}+\frac{C_{\mathrm{e}}}{q_{\max }}$,

where $q_{\mathrm{e}}$ is the amount of dye adsorbed at equilibrium, $C_{\mathrm{e}}$ is the equilibrium concentration of the dye, $q_{\max }$ is the maximum surface coverage for a monolayer and $K$ is the adsorption isotherm constant. According to Fig. 5, both MB and MV fulfil the requirements of the Langmuir model on both
Fig. 4 Variation of the amount of each dye adsorbed at equilibrium $\left(q_{\mathrm{e}}\right)$ as a function of initial dye concentration within the range of 0 and $1000 \mathrm{ppm}$ a MB on breadfruit peel, $\mathbf{b}$ MB on breadfruit core, $\mathbf{c} \mathrm{MV}$ on breadfruit peel and $\mathbf{d} \mathrm{MV}$ on breadfruit core $(50.0 \mathrm{~mL}$ dye solution, shaking time $180 \mathrm{~min}$, settling time $90 \mathrm{~min}$ )
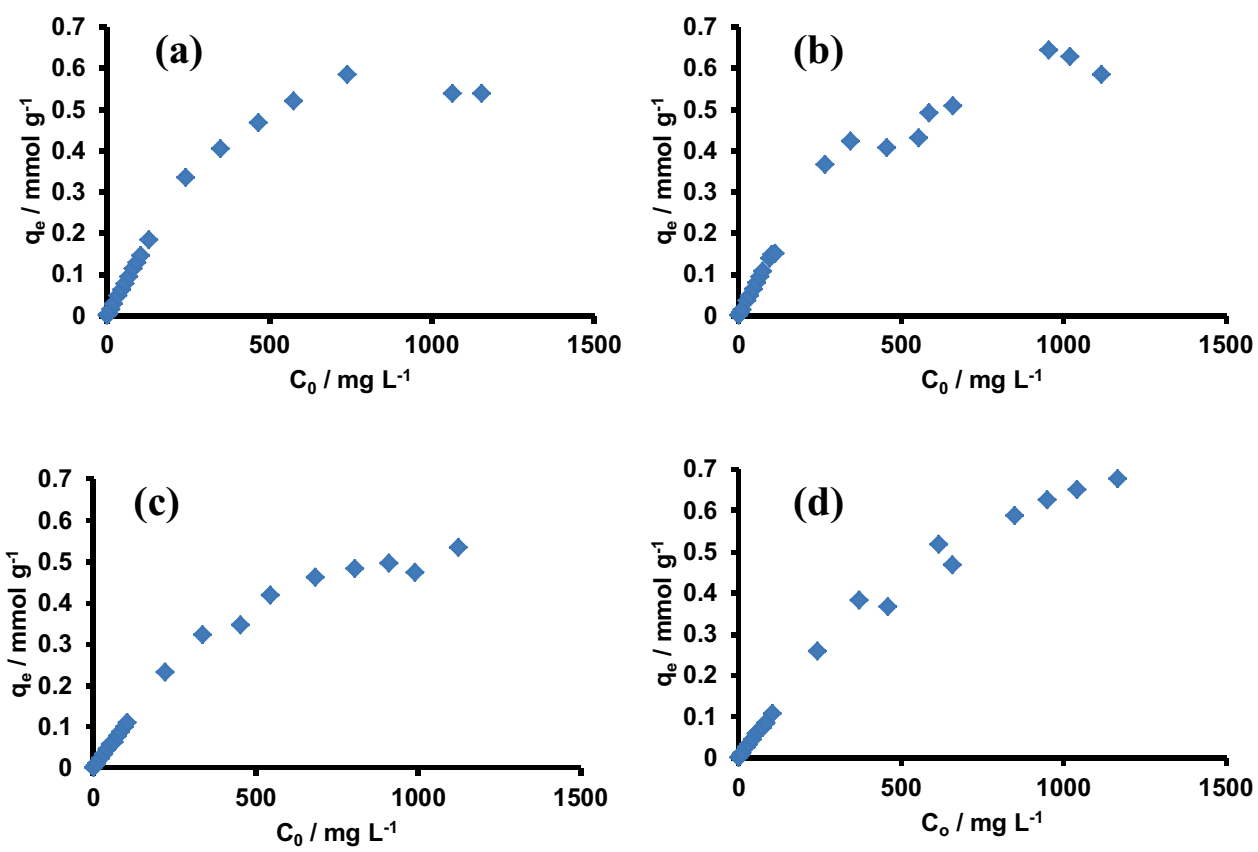
biosorbents. The isotherm constants of the Langmuir model and respective regression coefficients are shown in Table 3.

The $q_{\max }$ values obtained for both dyes on breadfruit core are higher than those on the peel (Table 3), as predicted earlier according to surface charge- $\mathrm{pH}$ variations (Fig. 2), where the surface charge density of the core is more negative at the $\mathrm{pH}$ of investigation. Further, the $q_{\max }$ values obtained for the removal of MB and MV by breadfruit waste are higher as compared to those observed for palm kernel fibre


Fig. 5 Langmuir adsorption isotherm model for biosorption of MB (filled diamond) and MV (filled square) on a breadfruit peel, $\mathbf{b}$ breadfruit core. Other parameters are as given in Fig. 4 and sunflower seed hull (Namasivayam and Sureshkumar 2008; Ofomaja et al. 2011; Hameed 2008) (Table 3), indicating the superior sorption ability of breadfruit waste for cationic dyes without any carbonization, which is comparable to activated carbon of natural substances. This is further supported by high $q_{\max }$ values reported for sorption of MB on jackfruit peel, another Artocarpus variety (Hameed, 2009), and for sorption of crystal violet on breadfruit skin (Lim et al. 2015).

\section{Kinetics study of biosorption of MB and MV on breadfruit peel and core}

The change in the concentration of each dye due to biosorption on each biosorbent as a function of time measured in short time intervals is shown in Fig. 6. According to Fig. 6a and $\mathrm{b}$, it takes less than $5 \mathrm{~min}$ to remove $50 \%$ of the maximum amount of MB removed by breadfruit peel or breadfruit core, indicating that kinetics of biosorption of $\mathrm{MB}$ on breadfruit waste is very fast. Consequently, kinetics models cannot be applied under these circumstances. Fast biosorption kinetics of MB on breadfruit waste provides a highly favourable situation for bioremediation of wastewater contaminated with MB. Another attractive feature is that the biosorption is irreversible as the formation of a monolayer is usually associated with chemical bond formation.

Kinetics of biosorption of MV on breadfruit waste is slower according to the rate of change in the amount adsorbed (Fig. 6). The bulky nature of the MV molecule despite its positive charge, as compared to that of MB (Fig. 1), is a possible reason for this observation. Due to slower kinetics, the rate constant of biosorption of MV on breadfruit peel or core can be estimated through kinetics models.

The pseudo first order rate equation is expressed as (Akar et al. 2010),

$\log \left(q_{\mathrm{t}}-q_{\mathrm{e}}\right)=\log q_{\mathrm{e}}-\frac{k_{1}}{2.303} t$

Table 3 Regression coefficients and adsorption constants of the Langmuir adsorption isotherm for biosorption of MB and MV on different biosorbents

\begin{tabular}{|c|c|c|c|c|c|c|c|}
\hline \multirow[t]{2}{*}{ Adsorbent } & \multicolumn{3}{|l|}{ MB } & \multicolumn{3}{|l|}{ MV } & \multirow[t]{2}{*}{ References } \\
\hline & $R^{2}$ & $K$ & $q_{\max }\left(\mathrm{mg} \mathrm{g}^{-1}\right)$ & $R^{2}$ & $K$ & $q_{\max }\left(\mathrm{mg} \mathrm{g}^{-1}\right)$ & \\
\hline Breadfruit peel & 0.994 & 0.0274 & 183 & 0.993 & 0.0132 & 222 & This work \\
\hline Breadfruit core & 0.979 & 0.0225 & 200 & 0.975 & 0.0083 & 307 & This work \\
\hline Palm kernel fibre & 0.918 & 0.0317 & 95 & - & - & 96 & $\begin{array}{l}\text { Ofomaja et al. (2011); } \\
\text { Hameed et al. } \\
(2008)\end{array}$ \\
\hline Sunflower seed hull & - & - & - & 0.985 & 0.0775 & 93 & Hameed et al. (2008) \\
\hline Jackfruit peel & 0.938 & 0.0291 & 192 & - & - & - & Maurya et al. (2006) \\
\hline
\end{tabular}


Fig. 6 The amount of dye removed from solution as a function of time during biosorption of each system a MB by breadfruit peel, $\mathbf{b}$ MB by breadfruit core, $\mathbf{c}$ MV by breadfruit peel, and $\mathbf{d}$ MV by breadfruit core $(50.0 \mathrm{~mL} 10 \mathrm{ppm}$ dye solution with $0.10 \mathrm{~g}$ of biosorbent)


where $q_{\mathrm{e}}$ is the amount of dye in the solution phase at equilibrium, $q_{\mathrm{t}}$ is the amount of dye present in the solution phase at time $t=t$, and $k_{1}$ is the apparent first order rate constant. The pseudo second order rate equation is given by (Akar et al. 2010),

$\frac{t}{q_{\mathrm{t}}}=\frac{1}{k_{2} q_{\mathrm{e}}^{2}}+\frac{t}{q_{\mathrm{e}}}$,

where $k_{2}$ is the apparent second order rate constant.

It is important that the concentration of one of the reactants should be kept unchanged to consider pseudo order kinetics of a chemical reaction. In the investigation of biosorption of MV on breadfruit peel/core, the concentration of MV can be assumed to be in excess during the initial reaction time period, and hence the change in the concentration of MV is much less as compared to that of the other reactant, i.e., the reactive moieties of the biosorbent. In this context, kinetics data obtained within the first 10-min period after initiation of sorption was used for detailed analysis. Figure 7 shows the pseudo first order kinetics plots constructed using such data. The $R^{2}$ values obtained for these plots for both peel and core of breadfruit are not close to 1.000 (Table 4). The pseudo second order plots result in higher $R^{2}$ values close to 1.000 , and hence, the biosorption of MV on breadfruit peel and core is expected to follow pseudo second order kinetics with rate constants of 153.5 and $31.7 \mathrm{~g} \mathrm{mmol}^{-1} \mathrm{~min}^{-1}$, respectively (Table 4 ). The rate constants determined in this investigation are higher than corresponding rate constants reported for biosorption of MV on other plant-based materials (Table 4), confirming the superior biosorption ability of breadfruit waste. As the
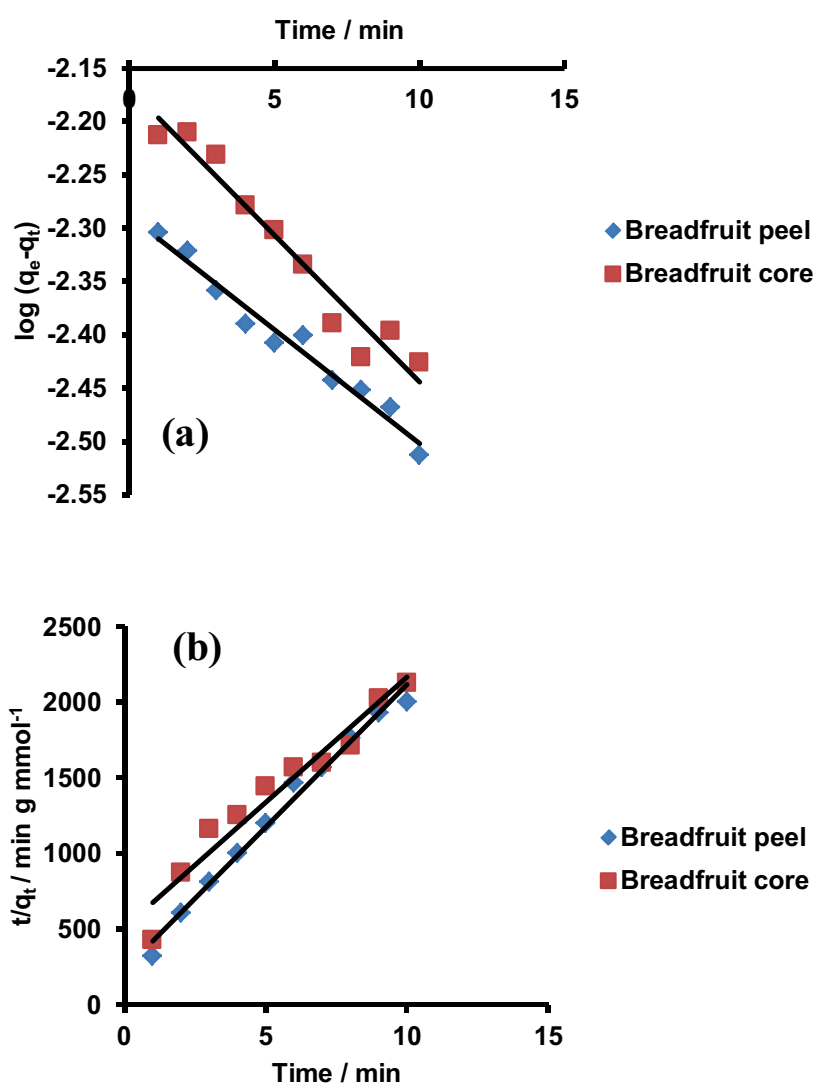

Fig. 7 Pseudo first order (a) and pseudo second order (b) kinetics models for biosorption of MV by breadfruit peel (filled diamond) and core (filled square) 
Table 4 Regression coefficients $\left(R^{2}\right)$ for linearized kinetics models for biosorption of MV on breadfruit peel and core and respective pseudo second order rate constants

Fig. 8 FTIR spectra of breadfruit core before (black line) and after (blue line) biosorption of $\mathbf{a}$ $\mathrm{MB}$, and $\mathbf{b} \mathrm{MV}$

\begin{tabular}{|c|c|c|c|c|c|}
\hline \multirow[t]{2}{*}{ Adsorbent } & \multicolumn{2}{|c|}{ Pseudo first order } & \multicolumn{3}{|l|}{ Pseudo second order } \\
\hline & $\begin{array}{l}\text { Rate constant } \\
\left(\min ^{-1}\right)\end{array}$ & $R^{2}$ & $\begin{array}{l}\text { Rate constant } \\
\left(\mathrm{g} \mathrm{mmol}^{-1} \mathrm{~min}^{-1}\right)\end{array}$ & $R^{2}$ & References \\
\hline Breadfruit peel & 0.048 & 0.969 & 153.5 & 0.987 & This work \\
\hline Breadfruit core & 0.062 & 0.947 & 31.7 & 0.971 & This work \\
\hline Bagasse fly ash & 0.022 & 0.906 & 8.9 & 0.999 & Mall et al. (2006) \\
\hline Mansonia wood saw dust & 0.025 & 0.989 & 0.4 & 0.999 & Ofomaja (2008) \\
\hline Sepiolite & - & 0.962 & 1.1 & 0.998 & Dogan et al. (2007) \\
\hline
\end{tabular}
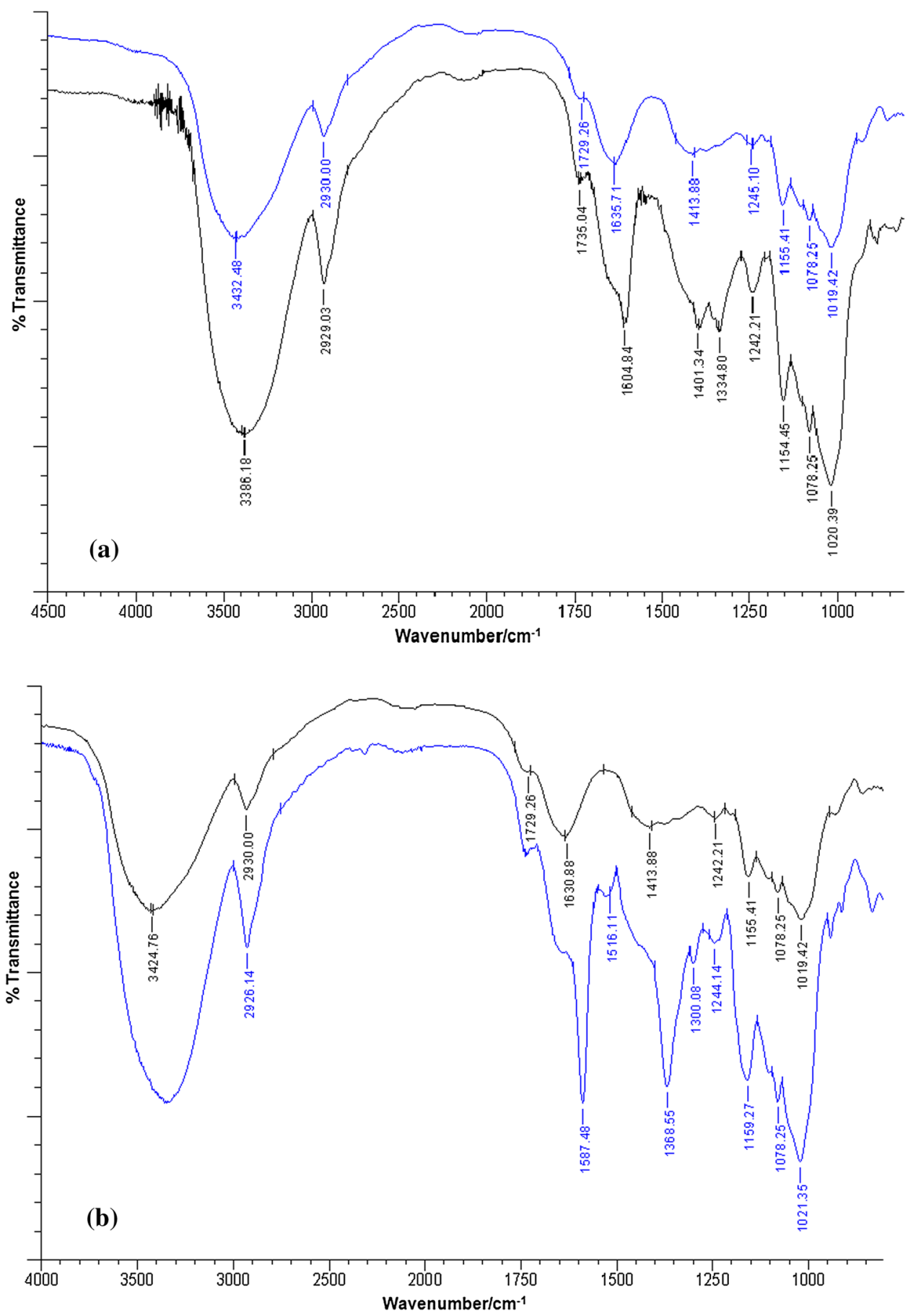
biosorption of MB and MV on breadfruit peel/core is limited to monolayer adsorption, there is a limited possibility for these dye molecules to transfer to the bulk of the adsorbent, and consequently, intra-particle diffusion would not probably take part in the mass transfer process.

\section{FTIR spectroscopic investigation of biosorption}

Figure 8 shows the FTIR spectra of breadfruit peel and core before and after biosorption experiments. The bands in the regions, 3387-3432, 2929-2930, 1615-1613 and $1019-1020 \mathrm{~cm}^{-1}$ observed before biosorption are assigned to be for stretching vibrations of $\mathrm{O}-\mathrm{H}, \mathrm{C}-\mathrm{H}, \mathrm{C}=\mathrm{O}$ and $\mathrm{C}-\mathrm{O}$ groups. Interestingly, the intensity of many peaks in the region from 1200 to $1750 \mathrm{~cm}^{-1}$ has significantly decreased after adsorption of MB and MV, which indicates that many organic functionalities with $\mathrm{C}-\mathrm{O}$ bonds are involved in chemical bond formation during biosorption. The location of new peaks and their assignments for bonding types are given in Table 5. As the kinetics experiments indicate that biosorption is of pseudo second order, it is suggested that two types of reactive centers be predominantly responsible for biosorption.

\section{Thermodynamics of biosorption}

Adsorption experiments conducted with 100 ppm dye solutions at different solution temperatures ranging from ambient temperature 24 to $70{ }^{\circ} \mathrm{C}$ clearly indicate that each dye is preferentially accumulated on the surface of breadfruit particles, leading to high adsorption equilibrium values. This is quantitatively determined by observing negative standard Gibbs free energy change $\left(\Delta G^{\Theta}\right)$ for adsorption of each dye on each biosorbent within the temperature range investigated providing necessary condition for spontaneity of biosorption (Table 6). Analysis of the variation of the $\Delta G^{\Theta}$ values with solution temperature is indicative of the

Table 5 Assignment of new peaks after adsorption of MB and MV on breadfruit peel and core

\begin{tabular}{|c|c|c|c|c|}
\hline \multirow[t]{3}{*}{ Functional groups } & \multicolumn{4}{|c|}{ Assignment $\left(\mathrm{cm}^{-1}\right)$} \\
\hline & \multicolumn{2}{|c|}{ Breadfruit peel } & \multicolumn{2}{|c|}{$\begin{array}{l}\text { Breadfruit } \\
\text { core }\end{array}$} \\
\hline & MB & MV & $\mathrm{MB}$ & MV \\
\hline $\mathrm{C}=\mathrm{O}$ stretching (carbonyl) & 1737 & 1729 & 1735 & 1587 \\
\hline $\mathrm{C}-\mathrm{C}$ stretching (aromatics) & 1608 & 1587 & $\begin{array}{l}1604 \\
1401\end{array}$ & 1516 \\
\hline $\mathrm{C}-\mathrm{H}$ rocking (alkane) & 1397 & 1367 & - & 1368 \\
\hline $\begin{array}{l}\mathrm{C}-\mathrm{O} \text { stretching (alcohols, carbox- } \\
\text { ylic acids, esters, ethers) }\end{array}$ & 1337 & - & 1334 & 1300 \\
\hline C-N stretching (aliphatic amines) & 1240 & - & 1242 & 1244 \\
\hline
\end{tabular}

fact that biosorption of MB on each biosorbent shows the maximum spontaneity at ambient temperature, while MB requires warm temperatures between 40 and $50{ }^{\circ} \mathrm{C}$ for the maximum biosorption. The standard enthalpy changes of all four systems are negative indicating exothermic behaviour. Further, more negative enthalpy changes observed for the biosorption of MB provides additional support for the Gibbs free energy changes stated above, which is probably due to the smaller size of MB molecules as stated earlier. Decrease in entropy, as expected for a biosorption system, is evident by observing negative standard enthalpy change values as given in the table.

\section{Conclusion}

Biosorption of MB and MV on breadfruit peel and core is highly efficient, and not much $\mathrm{pH}$ dependent between $\mathrm{pH} 4$ and $\mathrm{pH} 10$. However, competition of $\mathrm{H}_{3} \mathrm{O}^{+}$occurs in extremely acidic medium, and structural changes of the dyes occur in extremely basic medium, and hence ambient conditions are recommended in biosorption experiments. Biosorption of both MB and MV on breadfruit peel and core obey the Langmuir adsorption isotherm model with high regression coefficients, which favours monolayer coverage, suggesting that chemical bond formation occurs between dye molecules and reactive moieties on the breadfruit surface. Chemical bond formation is supported by observing the appearance of new IR absorption bands during adsorption of the dyes. The average $q_{\max }$ values obtained from Langmuir isotherm plots for biosorption of MB on breadfruit peel and core, and that of MV on breadfruit peel and core are 183, 200, 222 and $307 \mathrm{mg} \mathrm{g}^{-1}$, respectively. Biosorption of both dyes on both adsorbents are spontaneous and exothermic with the maximum extent of biosorption at ambient temperature for $\mathrm{MB}$, while it is observed between 40 and $50{ }^{\circ} \mathrm{C}$ for MV. Further, kinetics

Table 6 Thermodynamic data for bisorption of MB and MV on breadfruit peel and core

\begin{tabular}{|c|c|c|c|c|}
\hline \multirow[t]{2}{*}{ Temperature $\left({ }^{\circ} \mathrm{C}\right)$} & \multicolumn{2}{|c|}{$\begin{array}{l}\Delta G^{\Theta} \text { for } \\
\text { breadfruit peel } \\
\left(\mathrm{kJ} \mathrm{mol}^{-1}\right)\end{array}$} & \multicolumn{2}{|c|}{$\begin{array}{l}\Delta G^{\Theta} \text { for breadfruit } \\
\text { core }\left(\mathrm{kJ} \mathrm{mol}^{-1}\right)\end{array}$} \\
\hline & $\mathrm{MB}$ & MV & $\mathrm{MB}$ & MV \\
\hline 24 & -8.07 & -3.98 & -4.76 & -3.63 \\
\hline 40 & -6.93 & -4.95 & -4.05 & -4.37 \\
\hline 50 & -6.68 & -4.49 & -3.17 & -4.48 \\
\hline 60 & -5.54 & -4.19 & -2.54 & -3.93 \\
\hline 70 & -4.35 & -3.54 & -2.24 & -3.54 \\
\hline Average $\Delta H^{\Theta}\left(\mathrm{kJ} \mathrm{mol}^{-1}\right)$ & -32.19 & -19.24 & -20.60 & -13.96 \\
\hline Average $\Delta S^{\Theta}\left(\mathrm{kJ} \mathrm{mol}^{-1} \mathrm{~K}^{-1}\right)$ & -0.08 & -0.05 & -0.05 & -0.03 \\
\hline
\end{tabular}


and thermodynamics of biosorption of MB on both breadfruit peel and core are more favourable as compared to that of MV. The order of kinetics biosorption of MB on the adsorbents cannot be determined due to the high rate, while that of MV on the same adsorbents follows pseudosecond order kinetics with apparent rate constants of 153.5 and $31.7 \mathrm{~g} \mathrm{mmol}^{-1} \mathrm{~min}^{-1}$, for the peel and core, respectively. Further improvement of the extent of removal of $\mathrm{MB}$ and MV would be possible by chemical modification and/or processing the biosorbent to activate sorption sites.

Acknowledgements The authors are grateful to the Government of Negara Brunei Darussalam and the Universiti Brunei Darussalam for financial support in this research.

Open Access This article is distributed under the terms of the Creative Commons Attribution 4.0 International License (http://creativeco mmons.org/licenses/by/4.0/), which permits unrestricted use, distribution, and reproduction in any medium, provided you give appropriate credit to the original author(s) and the source, provide a link to the Creative Commons license, and indicate if changes were made.

\section{References}

Ahmad MA, Alrozi R (2011) Removal of malachite green dye from aqueous solution using rambutan peel-based activated carbon: equilibrium, kinetic and thermodynamic studies. Chem Eng $\mathbf{J}$ 17:510-516

Ahmad AA, Hameed BH (2010) Fixed-bed adsorption of reactive azo dye onto granular activated carbon prepared from waste. J Hazard Mater 175:298-303

Akar T, Celik S, Akar ST (2010) Biosorption performance of surface modified biomass obtained from Pyracantha coccinea for the decolorization of dye contaminated solutions. Chem Eng J 160:466-472

Bharathi KS, Ramesh ST (2013a) Removal of dyes using agricultural waste as low-cost adsorbents: a review. Appl Water Sci 3:773-790

Bharathi KS, Ramesh ST (2013b) Fixed-bed column studies on biosorption of crystal violet from aqueous solution by Citrullus lanatus rind and Cyperus rotundus. Appl Water Sci 3:673-687

Bhattacharyya KG, Sharma A (2005) Kinetics and thermodynamics of methylene blue adsorption on Neem (Azadirachta indica) leaf powder. Dyes Pigm 65:51-59

Dogan M, Ozdemir YO, Alkan M (2007) Adsorption kinetics and mechanism of cationic methyl violet and methylene blue dyes onto sepiolite. Dyes Pigm 75:701-713

Dogan M, Abak H, Alkan M (2009) Adsorption of methylene blue onto hazelnut shell: kinetics, mechanism and activation parameters. J Hazard Mater 164:172-181

Elkady MF, Ibrahim AM, El-Latif MMA (2011) Assessment of the adsorption kinetics, equilibrium and thermodynamic for the potential removal of reactive dye using eggshell bio-composite beads. Desalination 278:412-423

El-Sayed GO (2011) Removal of methylene blue and crystal violet from aqueous solutions by palm kernel fiber. Desalination 272:225-232

Farah JY, El-Gendy NS, Farahat LA (2007) Biosorption of Astrazone Blue basic dye from an aqueous solution using dried biomass of Baker's yeast. J Hazard Mater 148:402-408
Fei L, Soyi C, Gahee O, Tae SS (2012) Three-dimensional graphene oxide nanostructure for fast and efficient water-soluble dye removal. ACS Appl Mater Interfaces 4:922-927

Gupta VK, Suhas (2009) Application of low-cost adsorbents for dye removal removal - a review. J Environ Manage 90:2313-2342

Gupta N, Kushwaha AK, Chattopadhyaya MC (2011) Application of potato (Solanum tuberosum) plant wastes for the removal of methylene blue and malachite green dye from aqueous solution. Arab J Chem. https://doi.org/10.1016/j.arabjc.2011.07.021

Hameed BH (2008) Equilibrium and kinetic studies of methyl violet sorption by agricultural waste. J Hazard Mater 154:204-212

Hameed BH (2009) Removal of cationic dye from aqueous solution using jackfruit peel as non-conventional low-cost adsorbent. J Hazard Mater 162:344-350

Hameed BH, Mahmoud DK, Ahmad AL (2008) Sorption of basic dye from aqueous solution by pomelo (Citrus grandis) peel in a batch system. Colloid Surf A 316:78-84

Ju DJ, Byun IG, Park JJ, Lee CH, Ahn GH, Park TG (2008) Biosorption of a reactive dye (Rhodamine-B) from an aqueous solution using dried biomass of activated sludge. Bioresour Technol 99:7971-7975

Kumar KV, Kumaran A (2005) Removal of methylene blue by mango seed kernel powder. Biochem Eng J 27:83-93

Lee JW, Choi SP, Thiruvenkatachari R, Shim WG, Moon H (2006) Evaluation of the performance of adsorption and coagulation processes for the maximum removal of reactive dyes. Dyes Pigm 69:196-203

Li P, Su YJ, Wang Y, Liu B, Sun LM (2010) Bioadsorption of methyl violet from aqueous solution onto Pu-erh tea powder. J Hazard Mater 179:43-48

Lim LBL, Priyantha N, Chan CM, Matassan D, Chieng HI, Kooh MRR (2014) Adsorption behavior of methyl violet 2B using duckweed: equilibrium and kinetics studies. Arab J Sci Eng 39:6757-6765

Lim LBL, Priyantha N, Mansor NHM (2015) Artocarpus altilis (breadfruit) skin as a potential low-cost biosorbent for the removal of crystal violet dye: equilibrium, thermodynamics and kinetics studies. Environ Earth Sci 73:3239-3247

Mall ID, Srivastava VC, Agarwal NK (2006) Removal of orange-G and methyl violet dyes by adsorption onto bagasse fly ash-kinetic study and equilibrium isotherm analyses. Dyes Pigm 69:210-223

Maurya NS, Mittal AK, Cornel P, Rother E (2006) Biosorption of dyes using dead macro fungi: effect of dye structure, ionic strength and pH. Bioresour Technol 97:512-521

Maurya NS, Mittal AK, Cornel P (2008) Evaluation of adsorption potential of adsorbents: a case of uptake of cationic dyes. J Environ Biol 29:31-36

Mezohegyia G, Van der Zeeb FP, Fontc J, Fortunyd A, Fabregatc A (2012) Towards advanced aqueous dye removal processes: a short review on the versatile role of activated carbon. J Environ Manag 102:48-164

Mittal A, Gajbe V, Mittal J (2008) Removal and recovery of hazardous triphenylmethane dye, methyl violet through adsorption over granulated waste materials. J Hazard Mater 150:364-375

Namasivayam C, Sureshkumar MV (2008) Removal of chromium(VI) from water and wastewater using surfactant modified coconut coir pith as a biosorbent. Bioresour Technol 99:2218-2225

Ofomaja AE (2008) Kinetic study and sorption mechanism of methylene blue and methyl violet onto mansonia (Mansonia altissima) wood sawdust. Chem Eng J 143:85-95

Ofomaja AE, Ukpebor EE, Uzoekwe SA (2011) Biosorption of methyl violet onto palm kernel fiber: diffusion studies and multistage process design to minimize biosorbent mass and contact time. Biomass Bioenerg 35:4112-4123

Otero M, Rozada F, Garcoia A, Moran A (2003) Kinetic and equilibrium modelling of the methylene blue removal from solution 
by adsorbent materials produced from sewage sludges. Biochem Eng J 15:59-68

Ponnusami V, Gunasekar V, Srivastava SN (2009) Kinetics of methylene blue removal from aqueous solution using gulmohar (Delonix regia) plant leaf powder: multivariate regression analysis. J Hazard Mater 169:119-127

Priyantha N, Bandaranayaka A (2011) Interaction of Cr(VI) species with thermally treated brick clay. Environ Sci Pollut Res 18:75-81

Rafatullah M, Sulaiman O, Hashim R, Ahmad A (2010) Adsorption of methylene blue on low-cost adsorbents: a review. J Hazard Mater 177:70-80

Rahchamani J, Mousavi HZ, Behzad M (2011) Adsorption of methyl violet from aqueous solution by polyacrylamide as an adsorbent: isotherm and kinetic studies. Desalination 267:256-260

Safa Y, Bhatti HN (2011) Adsorptive removal of direct textile dyes by low cost agricultural waste: application of factorial design analysis. Chem Eng J 167:35-41
Suteu D, Zaharia C, Bilba D, Muresan A, Muresan R, Popescu A (2009) Decolorization wastewaters from the textile industry-physical methods, chemical methods. Industria Textila 60:254-263

Tripathi A, Ranjan MR (2015) Heavy metal removal from wastewater using low cost adsorbents. J Bioremediat Biodegrad 6:315. https ://doi.org/10.4172/2155-6199.1000315

Uddin TM, Rukanuzzaman M, Khan MMR, Islam MA (2009) Adsorption of methylene blue from aqueous solution by jackfruit (Artocarpus heterophyllus) leaf powder: a fixed-bed column study. J Environ Manag 90:3443-3450

Publisher's Note Springer Nature remains neutral with regard to jurisdictional claims in published maps and institutional affiliations 